\title{
The molding hypothesis: linking shell use with hermit crab growth, morphology, and shell-species selection
}

\author{
Alexander Turra ${ }^{1,2, *}$, Fosca P. P. Leite ${ }^{1}$ \\ ${ }^{1}$ Departamento de Zoologia, Pós-Graduação em Ecologia, Instituto de Biologia, Unicamp, Campinas, São Paulo 13083-970, Brazil \\ ${ }^{2}$ Present address: Laboratório de Biologia Aquática, Curso de Ciências Biológicas, Fundação de Ensino Octávio Bastos, \\ Campus II, São João da Boa Vista, São Paulo 13870-159, Brazil
}

\begin{abstract}
The 'molding hypothesis' (Elwood et al. 1979. Anim Behav 27:940-946) predicts that shell-species selection by hermit crabs may be influenced by past experience in shell use through shell-imposed alterations in crab morphology. The present study was designed to test this hypothesis and to further the understanding of plasticity in the shell-species selection in hermit crabs. Shell use was demonstrated to influence crab growth and morphology. Individuals reared in shells of Tegula viridula attained larger sizes than individuals in shells of Morula nodulosa. Crab growth was also dependent on crab sex, since males reached larger sizes and presented longer intermolt periods than females. The most conspicuous influence of shell utilization on crab morphology was in dorso-ventral flattening, which occurred on a decreasing scale with the shell species, as follows: M. nodulosa > Cerithium atratum $>T$. viridula. Crabs from all treatments and those collected in nature in shells of Olivella minuta chose mainly shells of $C$ atratum, but the previous experience of crabs strongly influenced their shell-species selection pattern. Individuals maintained in $M$. nodulosa shells selected $M$. nodulosa shells more frequently than individuals reared in $T$. viridula or $C$. atratum. The influence of past experience was demonstrated to depend on shell type, since patterns of shell-species selection of individuals reared in $T$. viridula or $C$. atratum were identical. These differences in the shell-species selection pattern directly reflected the differences in crab dorso-ventral flattening, i.e. dorso-ventrally compressed individuals (those in shells of $M$. nodulosa or $O$. minuta) showed a higher probability of selecting narrow-aperture shells than did 'rounded' individuals (those in shells of $T$. viridula or $C$. atratum). The weight of the selected shells at the end of the experiment depended on crab size instead of previous experience with different shell architectures.
\end{abstract}

KEY WORDS: Phenotypic plasticity · Shell-species selection · Resource selection · Growth · Molding hypothesis $\cdot$ Pagurus

Resale or republication not permitted without written consent of the publisher

\section{INTRODUCTION}

Debate on the relationship of environmental patchiness and predictability with natural selection led to an understanding of the evolution of habitat selection (MacArthur \& Levins 1967), where natural selection favors habitat choice in a patchy environment with predictable cues. In a parallel study on the behavior of hermit crabs (Lively 1988), it was hypothesized that each shell species was a different environment with particular architecture-related characteristics, and that shell preferences were selected in hermit crabs over evolutionary time. It was assumed that hermit crabs had intrinsic shell-species preferences. However, shell availability in nature is highly unpredictable within the geographic distribution of each species (Blackstone 1985, Leite et al. 1998), so that natural selection may favor plasticity in habitat (shell) use in hermit crabs (Hazlett 1995). In addition, a given hermit crab species may be exposed to different shell supplies in habitats 
with very different selective pressures, i.e. predation, hydrodynamism, structural complexity, and aerial exposure. In this way, one would ask if preferences for shells might be a plastic character, i.e. if shell preferences are habitat-induced? It has been demonstrated that shell-species preferences might vary ontogenetically (Elwood et al. 1979, Blackstone \& Joslyn 1984), but the extent to which they are due to availability or use of different shell types in different size classes was not investigated. Shell-size (Scully 1979) and shell-species (Blackstone 1985) preferences were demonstrated to vary between populations, and past experience was demonstrated to influence crab behavior (Jackson \& Elwood 1989, Hazlett 1995) and shellsize selection (Hazlett 1992, but see Hazlett 1996). The 'molding hypothesis' (Elwood et al. 1979, Elwood \& Kennedy 1988) was proposed to explain population differences in shell-species preferences, assuming that modifications in crab shell-preference after using a particular shell type would be a consequence of the effect of shells upon the crab, i.e. molding, modifying crab morphology. There are some records of alteration of crab shape in response to shell morphology in nature (McLaughlin \& Bailey-Brock 1975, Vermeij 1978) and in laboratory experiments (Blackstone 1984, Blackstone \& Joslyn 1984), but the effects of endogenous vs exogenous (intrinsic vs extrinsic) factors on shellspecies selection by hermit crabs are still controversial. While there is only indirect evidence that previous utilization of a certain shell species will predispose crabs to select them in future choices (Elwood et al. 1979, Hahn 1998), other studies have refuted this hypothesis (Blackstone 1984, Elwood \& Kennedy 1988). The present study experimentally tested the molding hypothesis and showed that it may explain patterns of shellspecies preferences in some hermit crabs.

\section{MATERIALS AND METHODS}

Species and study site. The São Sebastião Channel (southeastern Brazil) is a sheltered area composed of different environments, from rocky shores to mangroves. Hermit crabs are very conspicuous in the channel, especially in the intertidal Araçá region $\left(23^{\circ} 49^{\prime} \mathrm{S}\right.$, $\left.45^{\circ} 24^{\prime} \mathrm{W}\right)$. Pagurus criniticornis is an intertidal and shallow subtidal heterochelic species (Forest \& Saint Laurent 1967) common to muddy substrates in this region (Turra et al. 2000). This species has high activity levels during the entire day (Turra \& Denadai 2003) and frequently occupies shells of Cerithium atratum in the Araçá region (Leite et al. 1998, Turra \& Denadai in press). The hermit crabs also occupy other shell species such as Morula nodulosa, Tegula viridula, Olivella minuta, and Stramonita haemastoma (here- after referred to by genera names alone) in the channel (Leite et al. 1998). These shells have different architectures, from high-spires (Cerithium) to medium(Morula, Olivella, and Stramonita) and low-spires (Tegula). Shell aperture is also highly variable among species, being rounded (Tegula), imperfectly rounded (Stramonita and Cerithium), or narrowed (Olivella and Morula).

Laboratory conditions and experimental design. A closed water-circulation system was built for maintaining the hermit crabs. Six water tables $(0.6 \times 0.5 \mathrm{~m}$ each $)$ were connected to a reservoir in which the water was filtered and pumped. Thirty percent of the water was exchanged monthly and the salinity was fixed at $33 \%$. Water temperature was maintained at $23^{\circ} \mathrm{C}$. The bottom of the water tables was filled with biological filter plates and an auxiliary underwater pump was installed in the center of each. The orientation of the pump was changed daily in a clockwise manner to render water circulation homogenate. In each water table, 110 numbered hexagonal porcelain cups $(3 \mathrm{~cm}$ maximum diameter) were arranged in a beehive pattern, with 10 rows and 11 columns. A total of 660 individuals (1 per cup) were used in the experiment. This high number of individuals was used to balance crab mortality during the experiment. These cups were covered with a $2 \mathrm{~mm}$ mesh which was fixed with a silicon band. A larger central hole ( $5 \mathrm{~mm}$ ) was produced in the mesh to enable manipulation.

The hermit crabs were collected manually during low tides in the Araçá region in May 1999, transported to the laboratory, randomly separated (independent of sex or size) into 3 groups, and maintained in separated aquaria. Only small-sized individuals in shells of Olivella minuta were sampled and used in the initial experiment to control for crab size (shield length, 0.76 to $1.67 \mathrm{~mm}$ ) and past experience of shell use. All individuals were immature: none of the females presented ripe ovaries at the end of the experiment. A large amount $(>1000)$ of the tested shell species (shell treatments: Cerithium, Tegula, and Morula), with sizes matching the size range of the sampled hermit crabs, was offered to each group, i.e. each group was faced with only one shell type. After $3 \mathrm{~d}$ the crabs, now in the preferred shell-size of each shell treatment, were introduced into the water tables. This procedure allowed a complete standardization of the relative $\mathrm{crab} /$ shell size at the beginning of the experiment. The position of the treatments was systematically determined in the water tables, following a linear sequence (Cerithium/Tegula/Morula) from the first to the last cup available, to avoid a water-table edge effect. This arrangement placed all treatments in all available positions (rows and columns) and conditions in the water tables. 
The crabs were reared in isolation and fed every $3 \mathrm{~d}$ with commercial phosphate-free pelletized fish food. Feces and/or food remains and exuvia were removed daily. The exuvia were collected with a pipette and preserved in alcohol $70 \%$ for posterior measurements (shield length in $\mathrm{mm}$ : distance from the tip of the rostrum to the end of the hardened portion of the carapace). As crabs molted, new and larger shells were not supplied, as opposed to the method of Blackstone (1985), to simulate a shell limitation condition. The crabs were reared for the period of 6 molts.

Shell selection experiment. After the growth experiment, the crabs were submitted to a new shell selection experiment. The preference for shells in the 3 treatments (Cerithium, Tegula, and Morula) was tested for each individual. The previous shells were marked to enable their identification after the experiment. Twenty shells of each shell treatment and of variable sizes were offered to each crab for $24 \mathrm{~h}$, and the preferred shell type was then recorded. These experiments were conducted in circular glass cups (70 mm diameter $\times 100 \mathrm{~mm}$ height). A 'control' treatment for the shell-species selection was also employed, using individuals collected in shells of Olivella in nature. A true control was not possible because Olivella shells do not reach sizes that permit shell selection after crabs have grown. The results for this species revealed the shell-species selection pattern of the individuals in nature. After the experiment, the crabs were removed from the selected shell and the following measurements taken: shield length, shield width (widest portion), shield height (from sternum at the first pereopod to the highest part of the shield), as well as length and width (widest portion) of the right and left chela (propodus). The sex of the crabs was also recorded. The used (experimental) and selected shells were dried for $24 \mathrm{~h}$ at $100^{\circ} \mathrm{C}$ and then weighed.

Data analysis. The shield length of the exuvia collected during the experiment was plotted against cumulative molting time, using an extension of the classical Freundlich or allometric model $\left(y=\mathrm{a}+\mathrm{bx}^{\mathrm{c}}\right)$ for each tested individual. The von Bertalanffy growth function (Fotheringham 1976a) could not be fitted, due to the crab size-range in the experiment being limited. The initial size was set as Parameter a. The growth parameter (c) measured the shape of the growth function and could not be interpreted as a growth constant. Growth parameter, crab size at the end of the experiment, and total cumulative time needed to complete 6 molts were compared between shell treatments and by crab sex through ANCOVA, taking initial size as a covariate. Post hoc pair-wise comparisons (Scheffé's test) were carried out among shell treatments. Pearson's correlation was employed to relate crab final size, cumulative time, growth parameter (c), and crab initial size (a) with each other.

The influence of shell treatment and crab sex on crab morphology was evaluated using ANCOVA, with crab shield length as a covariate. Right-left chela asymmetry and right chela shape (length/width) were also compared among treatments. ANCOVA was followed by the Scheffé's test for multiple pair-wise comparisons.

To evaluate the effect of past experience on shellspecies selection pattern, a $4 \times 3$ contingency table (shells used vs shells selected; data of individuals collected in shells of Olivella in nature were included as a 'control') was analyzed using the log-likelihood G-test. Paired comparisons were done through partial $G$-tests. The effect of shell treatment on shell-weight selection was also tested. Crabs that selected shells of Cerithium and Morula were analyzed independently (only a few individuals selected Tegula and were not included in this analysis, see below). The weights of shells selected at the end of the experiment and the increment in shell weight - the difference between the weights of shells selected at the end and beginning of the experimentwere compared among shell treatments and sexes through ANCOVA, using crab shield length as a covariate. The Scheffé's test for multiple pair-wise comparisons was also employed. Statistical analyses were based on Zar (1999), with the significance level fixed at $5 \%$ (but see Bonferroni probability corrections, Sokal \& Rolf 1997).

\section{RESULTS}

\section{Influence of shells on crab growth}

A high variation in growth was recorded among individuals of Pagurus criniticornis. The size increment varied from 0.216 to $0.810 \mathrm{~mm}$ and the cumulative time needed to complete 6 molts varied from 73 to $182 \mathrm{~d}$. The mean value of the growth parameter was significantly smaller than the unit ( $\mathrm{c}=0.58$; isometric relationship: $\mathrm{c}=1$; Student's $t$-test, $\mathrm{p}<0.05)$, indicating negative allometry between time and crab size, i.e. size tended to stabilize through time. Initial size of the crabs was demonstrated to positively influence final size (Pearson's correlation; $\mathrm{n}=281, \mathrm{r}=$ 0.853, $\mathrm{p}<0.001)$ and cumulative time $(\mathrm{n}=281, \mathrm{r}=$ $0.447, \mathrm{p}<0.001$ ) and to negatively influence the growth parameter $(\mathrm{n}=281, \mathrm{r}=-0.230, \mathrm{p}<0.001)$ of the allometric model. In other words, larger crabs would present larger final sizes and longer intermolt periods, but smaller values for the growth parameter than did smaller crabs. A significant variation in initial size was recorded in the tested crabs (Table 1), 
Table 1. Pagurus criniticornis. Covariance analysis for the initial size (shield length, $\mathrm{mm}$ ), final size (shield length, $\mathrm{mm}$ ), cumulative growth time to complete 6 molts, and growth parameter (c) of the extended allometric model $\left(y=a+b x^{c}\right)$ of the individuals reared under different shell treatments (Tegula, Morula, and Cerithium). Shell treatment and hermit crab sex are fixed factors, and initial size is the covariate. $\mathrm{N}=281$; p-values calculated as corrected Bonferroni probability $\alpha^{\prime \prime}=\alpha / 4=0.0125$

\begin{tabular}{|lrrr|}
\hline Source of variation & df & $F$ & \multicolumn{1}{c|}{$\mathrm{p}$} \\
\hline Initial size & & & \\
$\quad$ Shell treatment & 2 & 7.331 & $<0.001$ \\
Sex & 1 & 0.500 & 0.480 \\
Shell $\times$ Sex & 2 & 0.946 & 0.390 \\
Final size & & & \\
Initial size & 1 & 818.737 & $<0.001$ \\
Shell treatment & 2 & 5.428 & 0.005 \\
Sex & 1 & 21.730 & $<0.001$ \\
Shell $\times$ Sex & 2 & 0.474 & 0.623 \\
Cumulative time & & & \\
Initial size & 1 & 70.963 & $<0.001$ \\
Shell treatment & 2 & 0.002 & 0.998 \\
Sex & 1 & 6.632 & 0.011 \\
Shell $\times$ Sex & 2 & 1.765 & 0.173 \\
Growth parameter & & & \\
Initial size & 1 & 14.266 & $<0.001$ \\
Shell treatment & 2 & 0.025 & 0.975 \\
Sex & 1 & 0.008 & 0.927 \\
Shell $\times$ Sex & 2 & 0.065 & 0.937 \\
& & & \\
\hline
\end{tabular}

with shells of Cerithium being selected by larger individuals than those of Tegula (Scheffé's test, $p<0.05$ ). To eliminate (or lessen) the effect of variable initial sizes on growth analysis, it was considered as a covariate in subsequent analyses. Final size was dependent on shell treatment (Tegula = Cerithium, Cerithium $=$ Morula, Tegula $>$ Morula) and on crab sex $(\mathrm{M}>\mathrm{F})$. The cumulative time to complete 6 molts depended on crab sex, with the intermolt period of males being longer than that of females. A positive relationship was recorded between cumulative growth time and final size $(\mathrm{n}=281$, $r=0.377, p<0.001)$. The shape of the growth function (growth parameter, c) depended neither on shell species nor on crab sex (Table 1), and was negatively correlated with cumulative growth time and final size ( $\mathrm{n}=281, \mathrm{r}=-0.421, \mathrm{p}<0.001 ; \mathrm{n}=281, \mathrm{r}=-0.196$, $\mathrm{p}=0.006$, respectively).

\section{Influence of shells on crab morphology}

Evaluation of the influence of shell type (treatment) on hermit crab morphology was done through covariance analysis. Shell morphology varied markedly among shell species: globose or low-spire (Tegula), elongated/medium-spire (Morula), and high-spire (Cerithium). They also showed significant differences in their aperture width when aperture length was considered as a covariate (ANCOVA; shell species: $F=853.732, \mathrm{df}=2, \mathrm{p}<0.001$; aperture length: $F=2220.006, \mathrm{df}=1, \mathrm{p}<0.001$; error mean-square $=$ 0.327, error df $=322$ ). Morula presented narrower apertures than did Cerithium which, in turn, presented narrower apertures than Tegula (Scheffé's test: $\mathrm{p}<$ 0.05 for all comparisons). A similar comparison revealed that shell weight also varied among species (Morula > Tegula $>$ Cerithium, Scheffé's test: $\mathrm{p}<0.05$ for all comparisons) when the dry weight of the soft parts of the gastropod was taken as a covariate (ANCOVA; shell species: $F=20.124$, df $=2, \mathrm{p}<0.001$; gastropod dry weight: $F=9868.572$, df $=1$, p < 0.001; error mean-square $=0.015$, error $\mathrm{df}=303$ ).

The influence of shells on hermit crab morphology was evaluated by comparing crab dimensions, taking crab shield length as a covariate. In fact, all tested variables were strongly dependent on shield length (Table 2). Crab sex significantly influenced the lengths of the right and left chela ( $\mathrm{M}>\mathrm{F}$ in both comparisons), the width of the right chela $(\mathrm{M}>\mathrm{F})$, and the right-left chela asymmetry $(\mathrm{M}>\mathrm{F})$.

Shell treatment influenced crab shield height and, although no differences were found in shield width among shell treatments, the individuals reared in Morula tended to present proportionally wider shields than those in Cerithium. Dorso-ventral flattening (shield height) was strongly dependent on shell treatment (Morula $>$ Cerithium $>$ Tegula; $\mathrm{p}<0.05$ for all paired comparisons). Shell treatment also had a significant influence on length of the right chela (Table 2), with individuals in Tegula presenting the largest chela and individuals in Morula presenting the smallest ones. Individuals reared in Cerithium showed intermediate values between these 2 species. A significant influence of shell treatment on right-left chela asymmetry was recorded, with individuals in Morula presenting smaller chela asymmetry than did individuals in Tegula and Cerithium (Scheffé's test; $\mathrm{p}<0.05$ for both comparisons). There was no interaction between shell treatment and crab sex in the analyses presented above (see Table 2).

\section{Influence of past experience on shell selection}

The preference for shells of Tegula, Morula, and Cerithium was tested for each individual subjected to the 3 shell treatments, and for individuals collected in shells of Olivella in nature (control). The hermit crabs selected mainly shells of Cerithium in all situations, but a significant influence of shell treatment in the shell- 
species selection pattern was evidenced (Fig. 1, $G=$ 27.66, df $=4, \mathrm{p}<0.001$ ). Individuals maintained in Morula shells selected Morula shells more frequently than individuals reared in Tegula and Cerithium (Morula vs Tegula: $G=15.70$, df $=2$, p < 0.001; Morula vs Cerithium: $G=22.42$, df $=2, \mathrm{p}<0.001$ ). This influence of shell treatment was demonstrated to depend on shell type because the patterns of shell-species selection of individuals reared in Tegula and Cerithium were identical $(G=1.60, \mathrm{df}=2, \mathrm{~ns})$.

The pattern of shell-species selection of the individuals collected in nature using shells of Olivella was closer (but significantly different) to that of the individuals reared in Morula $(G=$ 6.68 , df $=2, \mathrm{p}<0.05$ ) than to the patterns presented by individuals reared in Tegula $(G=$ 12.20, $\mathrm{df}=2, \mathrm{p}<0.001)$ and Cerithium $(G=$ 11.70, df $=2, \mathrm{p}<0.005$ ) (Fig. 1).

\section{Influence of shells on shell-weight selection}

The weight of the shells of Cerithium and Morula selected at the end of the experiment depended more on crab size than on shell treatment or crab sex (Table 3). A positive association between final shell weight and crab size was recorded (Pearson correlation, $\mathrm{n}=267, \mathrm{r}=$ 0.383, $\mathrm{p}<0.001$ ), i.e. the larger the crabs, the larger the shell weight at the end of the experiment. The weight increment in individuals that selected both Cerithium and Morula depended on shell treatment. For individuals that selected Cerithium, those reared in Tegula and Cerithium showed similar increments in shell weight, but they were larger than those recorded for individuals reared in Morula. This same tendency was recorded for individuals that selected Morula, although no significant differences were found in the multiple pairwise tests.

\section{DISCUSSION}

\section{Growth and morphology}

It is largely accepted that inadequate/small (Markham 1968, Fotheringham 1976a,b) or relatively heavy (Bertness 1981a) shells may reduce hermit crab growth. Shell architecture may also modulate hermit crab growth, with individuals reaching larger sizes in low- than in high-spire shells (Bertness 1981a, Blackstone 1985). The present study showed that shell type influenced crab growth and morphology. Individuals reared in low-spire shells (Tegula) were shown to grow more than individuals maintained in mediumspire Morula, although no difference was recorded between them and the crabs reared in high-spire Cerithium. These results may suggest that relative aperture width (Tegula $>$ Cerithium $>$ Morula) may be more crucial to crab growth than shell architecture.

Shell treatment influenced crab final size but not the time needed to complete 6 molts. Such differences in the final size among shell treatments were probably

Table 2. Pagurus criniticornis. Covariance analysis for the dimensions of individuals reared under different shell treatments (Tegula, Morula, and Cerithium). Shell treatment and hermit crab sex are fixed factors, and shield length is the covariate. p-values calculated as corrected Bonferroni probability $\alpha^{\prime \prime}=\alpha / 8=0.006$

\begin{tabular}{|c|c|c|c|c|}
\hline Source of variation & $\mathrm{N}$ & $\mathrm{df}$ & $F$ & $\mathrm{p}$ \\
\hline Shield width & 387 & & & \\
\hline Shield length & & 1 & 2378.367 & $<0.001$ \\
\hline Shell treatment & & 2 & 3.579 & 0.029 \\
\hline Sex & & 1 & 0.509 & 0.476 \\
\hline Shell $\times$ Sex & & 2 & 0.634 & 0.531 \\
\hline Shield height & 369 & & & \\
\hline Shield length & & 1 & 961.731 & $<0.001$ \\
\hline Shell treatment & & 2 & 27.120 & $<0.001$ \\
\hline Sex & & 1 & 1.782 & 0.183 \\
\hline Shell $\times$ Sex & & 2 & 0.627 & 0.535 \\
\hline Right chela length & 363 & & & \\
\hline Shield length & & 1 & 522.870 & $<0.001$ \\
\hline Shell treatment & & 2 & 7.357 & $<0.001$ \\
\hline Sex & & 1 & 161.639 & $<0.001$ \\
\hline Shell $\times$ Sex & & 2 & 0.702 & 0.496 \\
\hline Left chela length & 378 & & & \\
\hline Shield length & & 1 & 1355.543 & $<0.001$ \\
\hline Shell treatment & & 2 & 1.991 & 0.138 \\
\hline Sex & & 1 & 49.580 & $<0.001$ \\
\hline Shell $\times$ Sex & & 2 & 1.520 & 0.220 \\
\hline Right chela width & 366 & & & \\
\hline Shield length & & 1 & 205.339 & $<0.001$ \\
\hline Shell treatment & & 2 & 5.245 & 0.006 \\
\hline Sex & & 1 & 56.660 & $<0.001$ \\
\hline Shell $\times$ Sex & & 2 & 0.448 & 0.639 \\
\hline Left chela width & 380 & & & \\
\hline Shield length & & 1 & 802.885 & $<0.001$ \\
\hline Shell treatment & & 2 & 3.079 & 0.048 \\
\hline Sex & & 1 & 0.357 & 0.551 \\
\hline Shell $\times$ Sex & & 2 & 1.136 & 0.322 \\
\hline Right-left chela asymmetry & 295 & & & \\
\hline Shield length & & 1 & 30.300 & $<0.001$ \\
\hline Shell treatment & & 2 & 13.419 & $<0.001$ \\
\hline Sex & & 1 & 154.327 & $<0.001$ \\
\hline Shell $\times$ Sex & & 2 & 0.457 & 0.634 \\
\hline Right chela shape & 363 & & & \\
\hline Shield length & & 1 & 12.082 & $<0.001$ \\
\hline Shell treatment & & 2 & 1.065 & 0.346 \\
\hline Sex & & 1 & 1.300 & 0.256 \\
\hline Shell $\times$ Sex & & 2 & 1.549 & 0.241 \\
\hline
\end{tabular}



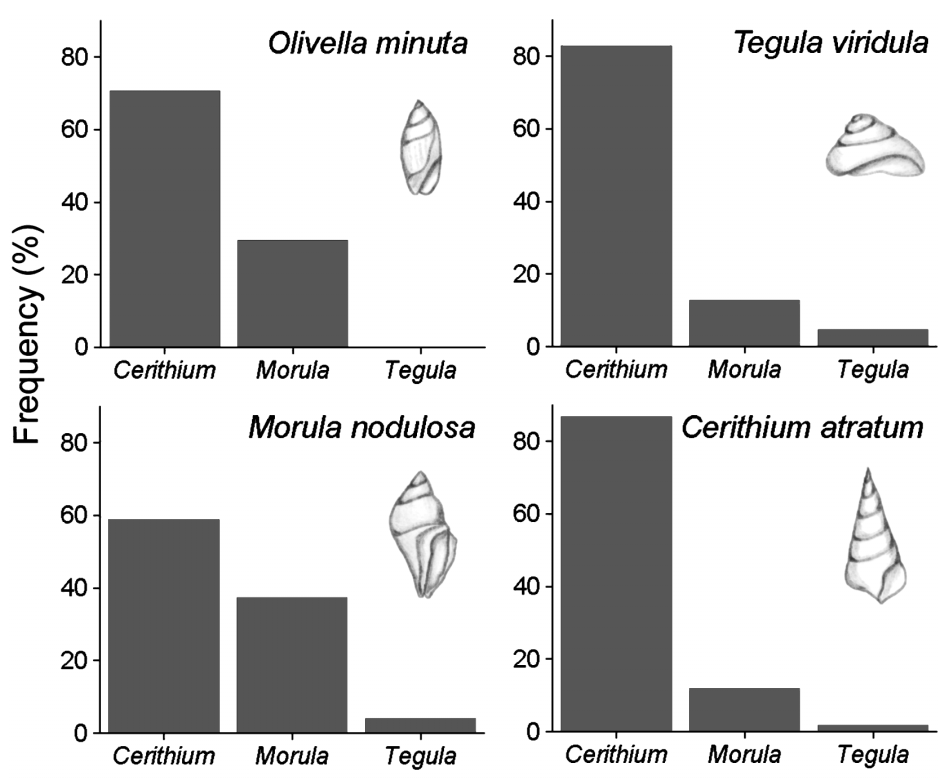

Fig. 1. Pagurus criniticornis. Patterns of shell selection of individuals collected in nature inhabiting shells of Olivella and reared under different shell treatments (Tegula, Morula, and Cerithium). Drawings represent general shell morphology (architecture)

caused by the slight tendency to higher growth rate (higher size-increment after molting) recorded for individuals reared in Tegula in comparison to those in Morula. The similarity in values of the growth parameter (c) among treatments revealed that the shape of the growth function (the allometric relationship) was not influenced by shell type.

Population studies revealed sexual dimorphism in interidal hermit crabs, with males being larger than females (Turra \& Leite 2000), and laboratory studies (Fotheringham 1976b, Blackstone 1985, but see Fotheringham 1976a) also demonstrated the higher growth rates of males in relation to females. Also in the present study, males presented larger final sizes and a longer intermolt period (longer cumulative time) than did females.

The influence of shell treatments was more evident on crab morphology than it was on growth. The most conspicuous effect of shell treatment (but not of crab sex) was on dorso-ventral flattening. Dorso-ventrally compressed crabs were recorded in narrow-aperture shells (Morula and Olivella). Dorso-ventral flattening has been previously observed in Dardanus guttatus (Vermeij 1978) and Clibanarius sclopetarius and Paguristes erythrops (A. Turra unpubl. data). In fact, shells are known to influence the shape of hermit crabs (Selbie 1921, Goldschmidt 1940, McLaughlin \& Bailey-Brock 1975, Blackstone \& Joslyn 1984, Blackstone 1985). Similarly, individuals reared in Morula, a nar- row-aperture shell, showed a tendency to present wider shields than individuals reared in Cerithium. Widened shields were also recorded as a response to previous utilization of medium-spire shells of Urosalpinx cinerea by Pagurus longicarpus in comparison to individuals in low-spire shells of Littorina littorea and Polinices duplicatus (Blackstone 1985). General shell architecture (low- vs high-spire) seems to be very important in determining crab growth and shape, although aperture shape, which represents the space hermit crabs use when not retracted into their shells, is probably more important than general shell architecture in molding crab morphology, as indicated by the significant relationship between crab dorso-ventral flattening and shell aperture shape.

Chela size and right-left chela asymmetry were also influenced by shell treatment and by crab sex. Individuals reared in Tegula showed larger (in length and width) right chela than individuals in Morula. Individuals in Cerithium presented intermediate values. Individuals reared in the low-spire Tegula and in the highspire Cerithium presented higher right-left chela

Table 3. Pagurus criniticornis. Covariance analysis for the weight $(\mathrm{g})$ of the shells selected after being reared under different shell treatments (Tegula, Morula, and Cerithium). Increment in shell weight (g), i.e. the difference between the weights of shells selected at the end and beginning of the experiment. Only crabs that selected shells of Cerithium and Morula were included in this analysis. Shell treatment and hermit crab sex are fixed factors, and shield length is the covariate. p-values calculated as corrected Bonferroni probability $\alpha^{\prime \prime}=\alpha / 2=0.025$

\begin{tabular}{|c|c|c|c|c|}
\hline Source of variation & $\mathrm{N}$ & df & $F$ & $\mathrm{p}$ \\
\hline \multicolumn{5}{|l|}{ Cerithium } \\
\hline Shell weight & 212 & & & \\
\hline Shield length & & 1 & 67.048 & $<0.001$ \\
\hline Shell treatment & & 2 & 0.837 & 0.434 \\
\hline Sex & & 1 & 0.062 & 0.804 \\
\hline Shell $\times$ Sex & & 2 & 0.101 & 0.904 \\
\hline \multicolumn{5}{|c|}{ Increment in shell weight 212} \\
\hline Shield length & & 1 & 2.242 & 0.136 \\
\hline Shell treatment & & 2 & 18.641 & $<0.001$ \\
\hline Sex & & 1 & 3.158 & 0.077 \\
\hline Shell $\times$ Sex & & 2 & 0.531 & 0.589 \\
\hline \multicolumn{5}{|l|}{ Morula } \\
\hline Shell weight & 54 & & & \\
\hline Shield length & & 1 & 30.201 & $<0.001$ \\
\hline Shell treatment & & 2 & 0.363 & 0.698 \\
\hline Sex & & 1 & 0.207 & 0.651 \\
\hline Shell $\times$ Sex & & 2 & 0.226 & 0.799 \\
\hline Increment in shell weight & 54 & & & \\
\hline Shield length & & 1 & 6.470 & 0.014 \\
\hline Shell treatment & & 2 & 3.469 & 0.039 \\
\hline Sex & & 1 & 0.026 & 0.874 \\
\hline Shell $\times$ Sex & & 2 & 0.845 & 0.436 \\
\hline
\end{tabular}


asymmetry than individuals reared in Morula. Blackstone (1985) showed that individuals in medium-spire shells of Urosalpinx cinerea presented relatively larger chela and larger chela asymmetry than individuals in low-spire shells of Littorina littorea and Polinices duplicatus. In addition, Blackstone (1985) did not record any difference in right chela shape (length/ width of the right chela) as a response to previous shell use. The differences between the findings of Blackstone (1985) and the present study reinforce the hypothesis that aperture shape is more important than shell shape in influencing crab morphology. Narrow apertures would limit chela growth and, as a consequence, reduce right/left chela asymmetry. In addition, males presented larger (right and left) and wider (right) chela than females, and showed a more pronounced right-left chela asymmetry. Blackstone (1985) also showed that males have a greater relative growth of claws than females. Such differences in chela size and asymmetry between males and females is expected to be quite evident in heterochelic species, such as P. criniticornis, and may be important in their reproductive behavior (Hazlett 1966).

\section{Shell-species selection}

The variability in shell use by hermit crabs is thought to be influenced by environmental factors such as shell availability (Bertness 1980, Leite et al. 1998), but crab preferences may also be important (Floeter et al. 2000, Turra \& Leite 2002). Previous studies have demonstrated that past experience of hermit crabs with shells may lead to shell-related behavioral plasticity. In fact, learning is an important component in such modifications in crab-shell relationships (Elwood et al. 1979, Jackson \& Elwood 1989, Hazlett 1992, 1996).

The small-sized individuals of Pagurus collected in nature in shells of Olivella (control) and those subjected to all shell treatments selected mainly the highspire shells of Cerithium. Preference for high-spire shells is common to other hermit crab species (Reese 1963, Bertness 1980, Blackstone 1984, 1985, Blackstone \& Joslyn 1984, Lively 1988, Turra \& Leite 2002), mainly to small-sized individuals. This suggests that hermit crabs may have innate preferences for certain shell types (high-spire), as also argued by Reese (1963) and Elwood et al. (1979).

The question of whether or not future shell-species choice in hermit crabs can be influenced by their previous experience (Elwood et al. 1979) is still challenging, because this hypothesis was not supported by subsequent studies carried out by Blackstone (1984), Elwood \& Kennedy (1988), and Hahn (1998). The present study demonstrated that, although crabs may pre- sent intrinsic preferences for certain shell types, previous experience with shells may influence their future choices. Individuals reared in medium-spire narrowaperture shells of Morula were more dorso-ventrally flattened and moved to treatment shells more frequently than individuals reared in low-spire roundedaperture Tegula and high-spire rounded-aperture Cerithium. The pattern of shell selection of the individuals reared in Morula was more similar to that of the individuals collected in nature in shells of the mediumspire narrow-aperture Olivella, which also presented significantly higher dorso-ventral flattening, than to the pattern exhibited by individuals reared in Tegula and Cerithium. The results do not show that previous shell experience may completely alter crab preferences to the extent that an abrupt switch in the preferred shell could occur, but they explain differences in shell utilization and selection patterns between populations subjected to distinct shell supplies.

\section{Shell-size selection}

Elwood et al. (1979) and Hazlett $(1992,1996)$ demonstrated that hermit crabs reared in low-adequacy shells selected relatively larger shells than crabs maintained in adequate ones. In the present study, crabs were reared in different shell types but with similar adequacies (all crabs were in optimal shells at the beginning of the experiment). The weight of selected shells at the end of the experiment was demonstrated to be more dependent on crab size than on shell treatment (shell architecture) or crab sex. Recent studies revealed that the relationships between hermit crab size and the weight of shells used in nature (Turra \& Leite 2002) and selected in free-access experiments (Turra \& Leite in press) did not depend on either crab or shell species. However, such differences were supposed to be significant if shells with quite different architectures were to be taken into account, as suggested by Bertness (1980) and Turra \& Leite (in press). The present study compared the shell-weight selection among quite different shell types (Tegula: globose; Morula: elongated; Cerithium: high-spire) and recorded the same results as in Turra \& Leite (in press), thus emphasizing the fact that relationships between crab size and shell weight did not depend on shell architecture.

\section{Consequences of preference switches due to shell utilization history}

The results of this study raise the following question: Why do the crabs not select Tegula, as they allow the crabs to grow as large as those in Cerithium? Bertness 
(1981b) found similar results for intertidal hermit crabs in Panama, as they also exhibited low preference for low-spire shells (Nerita). In fact, shell characteristics may have conflicting advantages for hermit crabs (Bertness 1981b, see Table 4). Low preference for lowspire Tegula could be a consequence of higher protection offered by other shell types against predation (Borjesson \& Szelistowski 1989, Kuhlmann 1992) and desiccation, which is a very important factor for intertidal hermit crabs (Taylor 1981, Turra \& Denadai 2001).

Bertness (1981a) argued that individuals from subordinate hermit crab species may evolve preferences for shell types of inferior value on an evolutionary time frame, while dominant species use and prefer optimal shells. The results in the present study show that such a switch in shell preferences may occur in an ecological time frame after only a few molting cycles. Clibanarius antillensis generally coexists with Pagurus criniticornis in intertidal areas in southeastern Brazil (Leite et al. 1998, Turra et al. 2000, Turra \& Leite 2001) and dominates the latter species in shell fights (Turra \& Denadai in press). Thus, Pagurus may be forced to use less preferred shells in nature. As growth proceeds, individuals may be molded by the shells and thus switch their shell-type selection pattern. This would cause a reduction in competitive interactions between species and, as a consequence, would favor coexistence. Further shell selection experiments would then reveal a low overlap in the shell selection pattern. However, it is important to note that such modifications would be a consequence of plasticity in phenotypic expression rather than the evolution of shell preferences.

Table 4. Conflicting advantages of the 3 gastropod species studied here, based on data in the present study and on literature information (after Bertness 1981b). +, small +++ , medium; and +++, high influence

\begin{tabular}{|c|c|c|c|}
\hline Parameter & $\begin{array}{c}\text { Tegula } \\
\text { (low-spire) }\end{array}$ & $\begin{array}{c}\text { Morula } \\
\text { (medium-spire) }\end{array}$ & $\begin{array}{c}\text { Cerithium } \\
\text { (high-spire) }\end{array}$ \\
\hline Anti-predator defence ${ }^{a}$ & + & +++ & ++ \\
\hline Influence on growth ${ }^{b}$ & +++ & ++ & +++ \\
\hline Influence on fecundity ${ }^{\mathrm{c}}$ & +++ & + & ++ \\
\hline Relative shell mass $^{\mathrm{d}}$ & 22.35 & 35.59 & 22.48 \\
\hline Depth to withdrawn ${ }^{\mathrm{d}}$ & 2.47 & 4.34 & 4.88 \\
\hline Resistance to desiccation & + & ++ & +++ \\
\hline \multicolumn{4}{|c|}{$\begin{array}{l}{ }^{a} \text { Shell architectural defenses (investment in shell material) based } \\
\text { on Vermeij (1978), Bertness }(1981 b, c) \text { and Turra et al. (unpubl.) } \\
{ }^{b} \text { This study } \\
{ }^{c} \text { Based on Bertness (1981a) } \\
{ }^{d} \text { Calculation based on the model for shell-species selection } \\
\text { (Lively 1988): relative shell mass - shell weight/dry weight of } \\
\text { gastropod soft parts (adapted); depth to withdrawn - shell } \\
\text { length (apex to siphonal canal)/aperture width (at the narrowest } \\
\text { point) } \\
\text { e Based on Bertness }(1981 b, c)\end{array}$} \\
\hline
\end{tabular}

Acknowledgements. We would like to thank Fundação de Amparo à Pesquisa do Estado de São Paulo (FAPESP, Proc. No. 98/00483-0) and CAPES for scholarship grants to A. Turra. FAEP partially funded this research. The Centro de Biologia Marinha of the Universidade de São Paulo (CEBIMar-USP) furnished the logistic support for field collections. P. Defendi and S. Tonico helped in the design of the laboratory structure. Thanks to A. C. A. Requel, C. P. F. Carvalho, C. Grininger, D. R. J. Ferreira, F. A. Berlini, L. O. Rached, L. R. Antunes, M. R. Denadai, M. C. Z. M. Bazo, O. J. Sírio, P. K. Boekelmann, R. B. França, S. K. Gobo, and S. R. Camargo for valuable help in laboratory work. Thanks to M. R. Denadai, M. R. Custódio, A. M. S. P. Vanin, R. M. Shimizu, T. M. Lewinsohn, C. A. Magalhães, and 3 anonymous referees for valuable comments on the manuscript, and to P. M. Sikar for the English revision.

\section{LITERATURE CITED}

Bertness MD (1980) Shell preference and utilization patterns in littoral hermit crabs of the Bay of Panama. J Exp Mar Biol Ecol 48:1-16

Bertness MD (1981a) The influence of shell-type on hermit crab growth rate and clutch size (Decapoda, Anomura). Crustaceana 40:197-205

Bertness MD (1981b) Conflicting advantages in resource utilization: the hermit crab housing dilemma. Am Nat 118: 432-437

Bertness MD (1981c) Predation, physical stress, and the organization of a tropical rocky intertidal hermit crab community. Ecology 62:411-425

Blackstone NW (1984) The effects of history on the shell preference of the hermit crab Pagurus longicarpus (Say). J Exp Mar Biol Ecol 81:225-234

Blackstone NW (1985) The effects of shell size and shape on growth and form in the hermit crab Pagurus longicarpus. Biol Bull 168:75-90

Blackstone NW, Joslyn AR (1984) Utilization and preference for the introduced gastropod Littorina littorea (L.) by the hermit crab Pagurus longicarpus (Say) at Guilford, Connecticut. J Exp Mar Biol Ecol 80:1-9

Borjesson DL, Szelistowski WA (1989) Shell selection, utilization and predation in the hermit crab Clibanarius panamensis Stimpson in a tropical mangrove estuary. J Exp Mar Biol Ecol: 213-228

Elwood RW, Kennedy H (1988) Sex differences in shell preferences of the hermit crab Pagurus bernhardus L. Ir Nat J 22:436-440

Elwood RW, McClean A, Webb L (1979) Development of shell preferences by the hermit crab Pagurus bernhardus. Anim Behav 27:940-946

Floeter SR, Nalesso RC, Rodrigues MMP, Turra A (2000) Patterns of shell utilization and selection in two sympatric hermit crabs (Anomura: Diogenidae) in south-eastern Brazil. J Mar Biol Assoc UK 80:1053-1059

Forest J, Saint Laurent M (1967) Campagne de la 'Calypso' au large des côtes Atlântiques de l'Amerique du Sud (1961-1962). 6. Crustacés Décapodes: Pagurides. Ann Inst Oceanogr Monaco 45:47-169

Fotheringham N (1976a) Effects of shell stress on the growth of hermit crabs. J Exp Mar Biol Ecol 23:299-305

Fotheringham N (1976b) Population consequences of shell utilization by hermit crabs. Ecology 57:570-578

Goldschmidt R (1940) The material basis of evolution. Yale University Press, New Haven

Hahn DR (1998) Hermit crab shell use patterns: response to 
previous shell experience and to water flow. J Exp Mar Biol Ecol 228:35-51

Hazlett BA (1966) Social behavior of the Paguridae and Diogenidae of Curaçao. Stud Fauna Curaçao Other Caribb Isl 23:1-143

Hazlett BA (1992) The effect of past experience on the size of shells selected by hermit crabs. Anim Behav 44:203-205

Hazlett BA (1995) Behavioral plasticity in crustacea: Why not more? J Exp Mar Biol Ecol 193:57-66

Hazlett BA (1996) Recent experience and the shell-size preference of hermit crabs. Mar Freshw Behav Physiol 28: $177-182$

Jackson NW, Elwood RW (1989) Memory of information gained during shell investigation by the hermit crab, Pagurus bernhardus. Anim Behav 37:529-534

Kuhlmann ML (1992) Behavioral avoidance of predation in an intertidal hermit crab. J Exp Mar Biol Ecol 157:143-158

Leite FPP, Turra A, Gandolfi SM (1998) Hermit crabs (Crustacea: Decapoda: Anomura), gastropod shells and environmental structure: their relationship in southeastern Brazil. J Nat Hist 32:1599-1608

Lively CM (1988) A graphical model for shell-species selection by hermit crabs. Ecology 69:1233-1238

Markham JC (1968) Notes on growth patterns and shellutilization of the hermit crab Pagurus bernhardus (L). Ophelia 5:189-205

MacArthur RH, Levins R (1967) Competition, habitat selection and character displacement in a patchy environment. Proc Nat Acad Sci USA 51:1207-1210

McLaughlin PA, Bailey-Brock JH (1975) A new Hawaiian hermit crab on the genus Trizopagurus (Crustacea, Decapoda, Diogenidae), with notes on its behavior. Pac Sci 29: 259-266

Reese ES (1963) The behavioral mechanism underlying shell selection by hermit crabs. Behavior 21:78-126

Scully EP (1979) The effects of gastropod shell availability and habitat characteristics on shell utilization by the inter-

Editorial responsibility: Otto Kinne (Editor),

Oldendorf/Luhe, Germany tidal hermit crab Pagurus longicarpus Say. J Exp Mar Biol Ecol 37:139-152

Selbie CM (1921) The Decapoda Reptantia of the coasts of Ireland. Part II. Paguridae. Sci Investig Fish Brch Ireland 1:1-68 Sokal RR, Rolf FJ (1997) Biometry. Freeman, New York

Taylor PR (1981) Hermit crab fitness: the effect of shell condition and behavioral adaptations on environmental resistance. J Exp Mar Biol Ecol 52:205-218

Turra A, Denadai MR (2001) Desiccation tolerance of four sympatric tropical intertidal hermit crabs (Decapoda, Anomura). Mar Freshw Behav Physiol 34:227-238

Turra A, Denadai MR (2003) Daily activity of four tropical intertidal hermit crabs from South-eastern Brazil. Braz J Biol 63(3):1-8

Turra A, Denadai MR (in press) Interference and exploitation components in interspecific competition between sympatric intertidal hermit crabs. J Exp Mar Biol Ecol

Turra A, Leite FPP (2000) Population biology and growth of three sympatric species of intertidal hermit crabs in southeastern Brazil. J Mar Biol Assoc UK 80:1061-1069

Turra A, Leite FPP (2001) Shell utilization patterns of a tropical rocky intertidal hermit crab assemblage: I. The case of Grande Beach. J Crustac Biol 21:393-406

Turra A, Leite FPP (2002) Shell utilization patterns of a tropical intertidal hermit crab assemblage. J Mar Biol Assoc UK 82:97-107

Turra A, Leite FPP (in press) Shell-size selection by intertidal sympatric hermit crab species. Mar Biol

Turra A, Jacobucci JB, Araújo FMP, Leite FPP (2000) Spatial distribution of four sympatric species of hermit crabs (Decapoda, Anomura). In: Klein JCV, Schram FR (eds) The biodiversity crisis and crustacea. Balkema, Rotterdam, p 261-273

Vermeij GJ (1978) Biogeography and adaptation. Harvard University Press, Cambridge

Zar JH (1999) Biostatistical analysis. Prentice Hall, New Jersey

Submitted: March 11, 2003; Accepted: September 30, 2003 Proofs received from author(s): December 19, 2003 